$$
\begin{aligned}
& \text { SF } 251 \\
& .455
\end{aligned}
$$


-1 


\section{"WHAT MAKES}

\section{THE MILK AND CREAM TESTS VARY SO?"}

An Address delivered before the Connecticut Daikymen's

Association, at Hartford, Conn., Jan. i6th, igoi,

$\mathrm{BY}$

J OSEPH L. H I L LS,

Director, Vermont Agricultural Experiment Station, BURLINGTON, VT. 


$$
S \frac{F^{21}}{H^{5}}
$$


"WHAT MAKESTHE MILK AND CREAM TESTS YARY SO?"

\section{JOSEPH L. HILLS,}

Director, Vermont Agricultural Experiment Station, Burlington, Vt.

This is a burning question in Connecticut as it is in Termont. It is, perhaps, not quite as important an issue since your State is not as thickly studded over with creameries and cheese factories as is the Green Mountain Commonwealth. Its area capable of cultivation is not much larger than yours, yet it contains within its borders over $25^{\circ}$ separate concerns, or, counting skimming stations, nearly $35^{\circ}$ places where co-operative dairying is in vogue. At over 300 of these milk and cream are bought and paid for by test, and at every one of these there is abundant querying as to the variations which appear in milk testing. What makes the milk and cream tests vary so? Doubtless the patrons of your creameries are asking the same question. I cannot hope this afternoon to resolve all their doubts, but perhaps that I may be able to throw some light upon the subject and help to make better feeling between creamery managements and their patrons. Some of the matters I shall mention may have little or no pertinence in Connecticut, owing to the differences in the methods of co-operative dairying in the two states.

Let us consider this matter under three heads :

I. Why does the milk or cream furnished by different patrons vary in test?

II. Why does the milk or cream furnished by the same patron when taken to different creameries vary in test? 
III. Why does the milk or cresm furnished by- the same patron, at the same creamery, vary one week with another, and one month with another; why does not the quality remain unchanged?

I. VARIAT1ONS IN TESTS BETWEEN INDIVIDUAL PATRONS.

Ist. Why does Smith's milk or cream test differ from that of Jones? Differences of breed, individuality, food, nervous excitement, environment, weather, the stage of lactation, and the management of the creaming devices may influence the result. Let us sketch some of these.

PREED.

Every observing dairyman appreciates that differences in cattle, due to the character of their breeding, are such that some cows give richer milk than others. The Channel Island cows have been bred through many scores of years with a specific purpose in view, to make a high grade milk; and, on the other hand, the cattle of Holland and Scotland have been bred generation after generation more particularly to make a large quantity of milk. While there are exceptions to every rule, still, speaking broadly, Jerseys and Guernseys give richer milk than do cows of other breeds. Smith's test outranks Jones' because long lines of breeding with a definite aim in view have implanted in his animals a tendency toward making a better grade of milk than can Jones' cows.

INDIVIDUALITY.

While the differences in breed are frequently concerned in the test variations as between one patron and another, the individuality of the animal is often quite as important: There are families within breeds. The cows of some families give relatively rich milk, and others in other families relatively poor milk. ()ne of my predecessors on this platform yesterday, with glib tongue and apt illustrations, aided by pictures of sundry types of cows, told this story far better 
than I can tell it. John Gould is a past master in the cow business, and his views upon the relation of type to performance already given in his volume may, well be referred to in this connection.

FOOD.

He who looks to food to grade up the quality of milk looks in vain. Food variations may increase the quantity of milk but seldom if ever bring about permanent changes in quality. If a cow is fed a very scant ration she may alter more or less the quality of milk given, but when a cow is changed from a good, palatable, plenteous ration to another of similar grade, but differently made up, no material change in the quality of the milk is likely to follow, provided the rations are normal. We have been trying for years at our station to persuade cows to change the quality of their milk, but at no time and in no way have we brought about a permanent change. When we have fed fat (vegetable oils, like corn, cottonseed, linseed and palm oils, etc.,) to the cow we have changed the quality of the milk to a slight extent; but we have hurt the quality of the butter far more than we have helped the fat percentage.

No Holstein cow can be wheedled into giving Jersey milk by any normal rational feeding, unless it be by semi-starvation. A starving or half-fed cow is apt to make richer milk as a consequence of her ill treatment-but far less of it.

\section{NERVOUS EXC1TEMENT.}

Such conditions as 'may be provocative of nervousness have more influence upon the quality of milk than most people are apt to think. I once heard a Maine dairyman say that in his judgment the best thing on a dairy farm was a dead dog, and that a coat of whitewash in the barn was a close second to it. A dog once thoroughly killed never again dogs cows, and thus one of the most common sources of bovine agitation is removed. Milk-making is a nervous function and in proportion as a cow becomes excited, in proportion as the nerve force which should be concentrated upon milk 
making, is distracted therefrom by any cause, dogging, hornflies, abuse, noise, etc., in that proportion there is likelihood -almost certainty - that the milk flow will be influenced. If I remember right Gov. Hoard tried a few years ago an experiment in this line. I believe he was the first man to urge that a cow be treated as if she was a lady; but once upon a time he abused a cow in order to know whether or not it would affect the quality of the milk. The cow was milked about half through and a sample of the latter portion of the milk was set aside; then a heavy pin was raked across her flank. She made a jump into the manger and was greatly excited. The milking was then finished and a sample taken. There was a difference of fifteen per cent in the amount of butter fat in the two halves of the milk, a difference of fifteen per cent in the amount of fat eliminated by the nervous equation.

Another experiment in the same line: One of our western experimenters fired blank cartridges in front of the cows immediately before milking. The explosions decidedly affected the quality of the milk. In our own experience an Ayrshire, temporarily in new and noisy surroundings, increased the quality of the milk without decreasing the flow, while another Ayrshire at the same time, treated in exactly the same manner, did precisely the reverse and shrank half in quality and a quarter in quantity. Anything that tends to make a cow nervously excited will be apt to affect the milking function and, as a rule, unfavorably.

Why should we expect a cow or herd of cows always to give, week after-week, the same quality of milk? Miik making is the cow's work, j11st as agricultural investigation and teaching and executive duties are my work, and the sundry farming operations, your work. Do we always work as well one day as another whether we feel well or ill? Though in the best of health do we do the same amount of work each day? Why should we expect a cow to do the same day after day? Her work is expressed by the milk she makes, and, largely, by the per cent of fat she puts into that milk. We should not expect of her what we ourselves cannot do. 
STAGE OF LACTATION.

The stage of lactation is another reason why Smith's milk test differs from that of Jones's. It is well known that cows tend to better the quality of their milk as they progress in lactation. Investigation has shown that cows differ greatly in this matter. Some vary but slightly and others largely as they pass from freshness to stripping. A farrow cow goes dry giving milk but little richer than when she came in; a pregnant cow going dry usually gives considerably richer milk than when she came in. Experiment has shown, moreover, that on the average the increase from calving to drying-off approximites 1.25 per cent. fat, that is to say a milk testing 4 per cent. at calving may test 5.25 per cent. of fat at stripping. Smith's milk may be made largely by strippers, while Jones' cows may be mostly fresh in milk.

It is now generally understood that the quality of the milk of the same herd varies decidedly from day to day, from milking to milking, and that, in order to represent correctly the weekly or monthly quality, it is necessary to take a composite sample. It will sometimes happen, however, that even when composite samples are used tests may vary one week with another fifty, sixty, or seventy points. I believe it is the duty of the creamery management in such case to verify the result by retest. Many patrons have an exaggerated idea as to this matter. For instance, a few years ago a creamery patron told me that he was being defrauded, that his test at the creamery one month was 3.90 and the next month 3.85 . These five points, 0.05 per cent., seemed to him enormous. No operator can take the same test in the same Babcock bottle and always read it twice alike. Two-tenths of one per cent. is not a wide difference between two tests, and three-tenths of one per cent. as between one month and another, even when the cows are in scant flow, is hardly a wide enough variation for cavil; more than that is of importance. But, as I shall say later on, one should not growl but investigate. 
MANAGEMENT OF THE CREAMING DEVICES.

Milk is creamed nowadays either by shallow setting, deep setting or centrifugal means The former old-styled and inadequate method is not followed in co-operative dairying and may be dismissed from further consideration here. Deepsetting systems vary somewhat in character and in efficiency. Smith may use a form capable of doing good work when conditions favor, and he may run it well. Jones may have a so-called dilution separator, sometimes, and well, called a delusion separator-and get quite likely a richer cream than Smith as a consequence, but a good deal less of it. Or one may have a centrifugal separator and the other, none; or both may have the same device and handle it in different manners.

Many of the items already referred to affect cream as well as milk tests. Breed, individuality, lactation changes, etc., play their part here. The term "Jersey Cream" is usually held to be a synonym for richness. As a matter of fact, Jer sey milk properly creamed in a deep-setting device is apt to make thinner cream than does the milk of other breeds containing smaller fat globules. In general, milk containing relatively small fat globules creams less thoronghly than that containing larger ones, but such cream as is thrown up is usually denser and richer. On this account as well as because of its well-known greater richness, stripper milk is apt to make a richer deep-setting cream than does new milk.

\section{VARIATIONS IN TESTS BETWEEN CREAMERIES.}

Why should Smith's milk or cream taken this week to Broun's creamery and next week to Robinson's creamery, test differently?

I presume this is seldom done in Connecticut. It is a common practice in Vermont; but it is an unwise procedure, since it accomplishes nothing.

When we go to bed at night we breathe a prayer in which are to be found the words "Lead us not into temptation." Human nature is so constituted that it of ten happens that a 
patron, who takes his milk or cream from Brown's creamery to Robinson's, is essentially leading the latter into temptation, into which he is apt to fall. He may feel inclined to raise the test, to make it read, or to report its reading, higher than it really is. In my judgment such a test is not a test of the milk, but of human nature; and the milk of human kindness is altogether too apt to be curdled by such a trial, as is the milk of the cow by the sulphuric acid of the Babcock method. Such a comparison has no standing and means nothing. There are better ways whereby one may find out whether Brown's work at the creamery is correct or is not correct. One may help himself or be advised by the experiment station.

HOW TO CHECK THE CORRECTNESS OF CREAMERY TESTING.

I believe that a Babcock apparatus should be located in every dairy community; and that there should be there, also, some young man or woman capable of running it in a satisfactory manner, whose services could be had by any one in the community at a small consideration. I do not advocate that all dairymen own Babcock apparatus. Some farmers are not fitted to run it properly. A Babcock incorrectly run is worse than none at all, since the results are more misleading than instructive. If the test apparatus and some man or woman who is careful and capable of running it are available, one may know, if he wishes to, whether his creamery is doing him justice or not.

If the community is unwilling to combine in this way, its dairymen may turn to the experiment station, an institution which is helpful to hundreds of dairymen in the State in this very way. It is a common thing up our way for Smith, who doubts whether Brown's test is correctly or honestly made, to take a sample and express it to the experiment station ; and then if its test differs from Brown's there is music in the air.

You will ask, perhaps, how the station knows that the sample that Smith sends has not been tampered with. If Smith is a rogue, if for any reason he is bound to make his creamery wrong, whether or no, it is easy for him to manipulate the sample. So can 
Brown tamper with samples. Yet if the men are sincere and anxious to know the truth, there are ways in which they can insure accuracy. Some little time ago the Vermont station put out a four page bulletin,- - reprinted at the end of this article,--giving methods of sampling milk and cream. This has been printed in poster form and was sent last spring to every Termont creamery and cheese factory with the request that it be posted near the weigh can. WVe give three schemes for sampling milk or cream whereby the patron who desires to check the testing work of the cream. ery may do so; first, the creamery sample may be halved, second, the creamery man may be required to take duplicate samples, and, third, a patron may take his sample for him self. Neither of these methods of sampling will ensure absolute accuracy. Errors of omission or commission, of igno. rance or intent, may be made. If the creamery samples be halved, if Brown is asked to furnish half of it that it may be sent to the station, it is located, prior to halving, in the control of one of the interested parties, the creamery man; and if he is inclined he may tamper with the sample instead of with the result. If the second method is used, if every time Brown's operative puts a gill of milk or a measure of cream into his sample jar he puts one into the jar which the patron holds, the objection may be urged that the sample is in the hands of the other interested party, the patron. If the dairyman takes his own sample at home, he may be ill informed as to the necessary precautions in sampling, or careless, or, indeed, intentionally deceitful, and the sample be not truly representative. In short there is no way in which the experiment station can be certain that the samples sent it are correctly taken. Hence we are careful in our reports to those sending us samples to disclaim all responsibility as to the accuracy of sample taking. I think, however, that the bulletin to which I have referred, which was sent to be posted at every creamery and cheese factory in Vermont, which was mailed by thousands throughont our state to the station mailing list, and which concludes this article, does help to make the samples that cone to us more niniform and trustworthy: 
III. VARIATION IN TESTS WITHIN THE SAME HERD.

Why is it that Smith's milk or cream taken to Brown's creamery varies one month with another? Why does it not test evenly?

Several of the reasons cited under the first head apply here.

\section{LACTATION CHANGES.}

The change in lactation of the cows is one important reason why there should be variation. The general tendency of the herd will be as the cows go along in lactation to give somewhat richer milk. While there are many exceptions, the general rule is that cows coming in in the spring will give a fairly even grade of milk for the first five months in their lactation, and then increase in quality until they go dry. If they are farrow cows, quality changes but little as time goes on. If an all-the-year-round dairy is kept there should be less change on this account.

These same changes pertain to the cream. The richer milk is apt to make richer cream for reasons hitherto pointed out, if it is handled by a deep-setting device. Centrifugal separators, however, are no respectors of rich or of poor milks. A rich cream may be made from one and a poor cream from the other, according to the setting of the creamscrew or regulating device. If, however, this remains unaltered and the same proportion of milk is taken as cream from the rich and from the thin milk, creams will vary . accordingly.

For example if one dairyman has 1000 pounds of new milk testing 3 per cent., and the other, rooo pounds of stripper milk, testing 5 per cent. and each takes 100 pounds cream and 900 pounds skim milk, the former would have a cream testing nearly 30 per cent. and the latter, one containing approximately 50 per cent. fat.

\section{WEATHER.}

Stress of weather is another cause of variation. We have given much time at the Vermont station to the study of the 
effect of temperature upon the milk-flow. Our results irdicate that the quality of a cow's milk alters inversely to temperature changes. When the temperature rises the tendency is for the quality of the milk to drop; when the temperature falls the tendency is for the quality of the milk to rise. There are, however, many exceptions to this rule. No attempt has been made to test this matter in long periods but only as to daily or weekly fluctuations.

SURROUNDINGS.

The environmental differences, the nervous excitement of the cow already mentioned, as they vary from time to time, may cause fluctuations in the quality of the cow's milk. The change from barn to pasture, or the reverse, lack of water, poor water, drying pastures, new milkers and the like, may and often do have influence. Then, too, it must be confessed that there sometimes occur fluctuations in the quality of the milk of a cow, and, occasionally, of a herd for a week or more, for which no rational explanation can be offered, changes which, because of care in sampling and testing and the conditions surrounding the operations, are removed beyond all likelihood of being due to error rather than to fact. There is much that we do not know about cow nature and cow doings in milk-making. And here, as ever, those who know the most are those who impute the least, while those less well informed are the more suspicious of wrong doing:

An editorial in a recent number of Hoard's Dairyman is very much to the point in this connection. It says :

"The cow is not a machine that will turn out the same quantity or quality of milk from day to day, and consequently the milk varies according to the physical and, perhaps, mental condition of the animal. The physical comfort or discomfort of the animal is reflected in the milk pail, and if the great mass of dairymen would only recognize this fact, it would have a beneficial effect on the state of the pocket book.

In a careful record of the yield of a herd of cows for several years the following facts were noted: 
They varied in quality of milk from one milking to the next, and from day to day, the quality rising and falling without apparent cause.

The changes were usually within I per cent of fat, but one cow changed 2.68 per cent. in two days.

The average change during the period of lactation was I.34 per cent., and the greatest change 2.78 per cent.

The above herd was exceptionally well taken care of and sheltered, and the changes in quality of milk were thus much less than would be noticed in cases of animals kept under less comfortable conditions.

The dairymen should remember that exposure to cold, drinking large quantities of cold water, exposure to cold rain, fright, worry, heat, flies, and dogs, walking several miles over poor pasture for food, starvation, soothing the cow with kicks or milking stool, will all remove fat from the milk and make such treatment more expensive than good shelter and kind treatment.

When a patron's milk shows a low test, let him make a careful examination of conditions at home before he lays the blame on the butter-maker or the test."

THE CREAMING DEVICES.

Actual variations in the management of the creaming devices, known or unknown to the operator, account to quite an extent for variations in the cream output. For the sake of convenience and clearness, let us consider the possibilities of variation in the deep setting and centrifugal methods each by itself. No pretense is made that all possible causes of variation are covered.

DEEP SETTING.

Temperature-Completeness of deep-setting creaming is largely dependent upon the proper temperature of the water. The density of the cream is also affected by this factor. A warm water ( $45^{\circ}$ and upwards) means poorer creaming and less of a richer cream. Colder water means better creaming and a less dense cream. 
Length of setting-The shorter the time, as a rule, the thinner the cream.

Delays in setting-Delays in setting are apt injuriously to affect creaming, and, perhaps, to modify the fat percentage.

Deep-setting creams from different sources may vary over quite a wide range, containing seldom, if ever, more than 25 per cent. fat, or less than I 2 per cent. I have seen quite wide differences from day to day in the same herd with the same milk for which no adequate cause could be assigned.

SEPARATOR.

A good separator properly and uniformly run ought to turn out from milk of essentially even quality a cream of a practically unaltered character. But milks from day to day do change in their fat percentage, even though herds be of considerable size; and, consequently, creams vary accordingly. As a rule, however, one week with another, if no change occurs in the setting or the running of the mechanism, and barring the extreme changes of the latter part of the lactation, there should be only minor changes in fat percentages.

Changes in device for regulating thickness of cream-All separators have means of controlling the proportions of the milk taken as cream and as skim milk. If in any way, accidental or intentional, the setting is changed, the quality of the cream is affected. Accidental changes often occur. The outlet becomes clogged, a hair lodges there, a chip or filing of steel, or a bit of curd or some speck of dirt gets in, the cream flow is retarded and its richness affected.

Incorrect ruming-Too low or too high speed or feed, a trembling bowl, a machine ill cleansed, out of repair, or out of balance may and do affect results. I have known positive flaws to exist in the mechanism which modified results.

While not exactly germane to the subject I may be permitted, I trust, to say a word in answer to the very common question at meetings of this kind - What is the best separator?

This is one of the most common questions asked of the 
station. Our present feeling in the matter is that there is not, of necessity, any one make that is "best" in. all points ; that machines of all the more prominent makes are capable of doing a good grade of work when properly handled ; that, since good skimming is the rule, other points, such as initial cost, durability, probable repair bills, ease of operation, etc., are now more important; and, finally, since flaws may occur in individual machines of any make, that agents' claims and records of other machines of the same make are of less value, touching the quality of skimming, than is the analysis of the skimmilk of the individual machine offered. Many farmers in Vermont have bought separators on the condition that the skimmilk should be submitted to the experiment station for analysis, purchase to follow its favorable, and rejection its unfavorable report. The biyer thus has, free of expense, the advantage of the advice of disinterested experts, which moreover, is given in ignorance of the kind of machine under trial.

We are now ready to consider a phase of the question which I want to treat with the greatest care as to the words I use and the impression I leave.

I believe that among the serious factors in this matter of milk test variation are the errors of the testing operation. Let us discuss this possibility of error in the manipulation of the test under the sundry subheads, sampling. apparatus, errors of ignorance and errors of intent.

SAMPLING.

By no art of legerdemain can a milk analyst return a correct result from an incorrect sample. I am inclined to think that a considerable part of the variation between tests is due to imperfect methods of sampling.

Three methods of sampling are more commonly in vogue, the dipper method, the core method and the automatic method. The latter is applicable to milk sampling only, unless very large quantities of cream are brought to the factory. The two former are used for both milk and cream. 
The first named is the most widely used of the three. From the mass of milk or cream more or less (almost always less) thoroughly stirred (and, indeed, often not stirred at all) a gill or less is dipped for a sample. Such procedure may result in an accurate sample and it may not. Fresh milk, not creamed, well aerated and stirred, carted over rough roads and drawn from cows not giving large fat globules, may be accurately sampled thus with a minimum amount of stirring. (On the contrary, milk which has creamed, which is a day or more old, from Jersey or Guernsey cows, but slightly shaken in transportation, if, in considerable quantity, cannot be mixed with sufficient thoroughness to insure accurate sampling by superficial stirring. The Vermont station several years ago did much work in investigating methods of milk sampling, as a result of which we are prepared to say with a fair degree of assurance, that when five hundred pounds of milk somewhat creamed is delivered at the factory, there is no surety of the accuracy of the sample taken therefrom by the dipper method, unless it be stirred for from two to four minutes, round and round and up and down. Hence it is wise to consider the advisability of choosing some method which is more likely than this one to insure accurate sampling.

While there is no method of sampling which is not open to defeat through improper handling, there are methods wherein there is a greater proportion of automatic action than in the one just considered. The coring method is one of these. Several devices designed to core milk or cream are used. The Scovell sampler, which was used in the World's Fair tests in $\mathrm{r} 893$, is a fair type of this class of implement. It consists of a small brass tube with a perforated sliding cap at the bottom. It is lowered into the fluid slowly so that it will flow into the tube until it strikes the bottom, when the perforated cap slides over and closes the tube, thus procuring a core. This method of sampling, provided the cream is not separated in clots and the milk is neither loppered or frozen, will take a correct sample if carefully used. It is more likely to take a correct sample than is the dipper method, or, rather, is less likely to take an incorrect 
one. This method is much to be preferred to the dipper method for cream sampling.

This is, however, a method applicable to milk but not to cream sampling which suits me better than either of these, known as the automatic method. The apparatus for this consists of a weigh can covered by a cone-shaped wire cloth or wire mesh, and some means of withdrawing a small stream from the outflowing milk. This small stream may be abstracted by means of a small faucet, set at the bottom of the can within a few inches of the outlet gate, or by means of a hole punched in the conductor head or spont. The petcock or faucet modification of this device on the whole approves itself to me rather than the other.

The milk being weighed, both the gate and the pet cock. are opened and remain opened until all the milk has run out. A small proportion, varying according to the size of the orifice of the petcock, is canght. The relatively small amount of milk caught in the pail is very readily mixed, and the gill taken. The fine wire-mesh strainer distributing the milk into a thousand streams serves to quite an extent to mix it. I do not advocate the antomatic device unless the fine wire mesh be used.

Governor Hoard of Wisconsin states that the first device of that kind used was placed in his creamery, and is ret in vogue. As used by him a hole is punched in the bottom of the conductor running from the weigh can to the vat at a point near the vat. The milk when turned into the weigh can is mixed to quite an extent; the gate is then lifted and it pours out in a rush and it mixes itself running and tumbling over and over, and just as it nears the vat, a drup or so from every pound of milk falls into the jar. The drip is obtained as far from the weigh can as possible.

This method is not only theoretically accurate but has proved to be practically correct in thousands of trials; and it has been found to obviate a large part of the errors and annoyances of sampling. The device has been tried over and over again as against extreme care in sampling, and has proved, I think, correct in every case. It may be mismanaged, but it more surely takes an accurate sample than any 
other practicable method since the sample in part takes 1 tself, regardless of care or lack of care on the operative's part.

APPARATUS.

A law was passed at the last session of the Vermont legislature which required, among other things, that the Babcock test apparatus used in dividend making be accurate. I have on this table six bottles. Three are good and three are bad. Can you tell which is which? The manufacturer "guarantied" that all were accurate; yret notwithstanding this guaranty some were excessively inaccurate. Here is an accurate cream bottle. How do we know it is so? Not because the manufacturer says so, but because, in accordance with Vermont law, the station of that state has found out whether it is accurately graduated or not, and certified thereto, if correct, by grinding indelibly upon the neck of the bottle VTExSt.

One creamery insisted that we send back all the bottles we found to be incorrect. We did so. I doubt whether they were used, however, afterwards; for we ground indelibly upon six places on each bottle the word BAD.

We found that one out of every thirty pieces (three per cent.) of the apparatus in use before the law was enacted was inaccurate, some exceedingly so. All the apparatus that is being sold by the Vermont supply houses to-day is correct, because it is all submitted to our inspection and only the correct pieces shipped them. As it comes to us now less than one-half of one per cent., one in two hundred, is incorrect. Clearly this section of the law is of benefit.

The law is imperfect however. It shutld cover the accuracy of the centrifugal testing machines. There are centrifugal testing machines in use at creameries so constructed that they cannot give correct results; and many are worn out. The law should provide for the inspection of these machines and prohibit the use of such as yield incorrect results.

ERRORS OF IGNORANCE.

The Vermont law requires that every operator of the Bab- 
cock test for dividend-making shall be examined as to his knowledge of the method of its operation; and that he shall secure a certificate from the dairy school of the University of Vermont and State Agricultural College that he is competent and well qualified to perform the work.

The law has forced many operators to perfect themselves so they could pass the examination and get a license, who otherwise would have tested with but a half knowledge of the process. There have been tested up to Jan. I, I90I, over 21,500 milk and cream bottles and pipettes and 342 would-be licensees. Had it not been for the law $34 \mathrm{I}$ incorrect bottles and ${ }_{4} \delta$ incompetent operators, unable to test correctly even under conditions when if ever they would have striven to do their best, would have been to-day adjudicating the value of milk at Vermont creaneries and factories. Large numbers of incorrect pipettes and acid measures have been detected and regraduated and are not included in this showing. A considerable number of operatives were refused licenses on the first examination, but were granted them after they proved on second trial, that they had learned how to test milk. Every man testing in Vermont to-day at least knew how to test when he took the examination. Whether in actual work he does as well as he knows is another story. I see no reason why a law of this sort should not work well in Connecticut. It works no hardship to any one, provides for the removal of incorrect apparatus and keeps incompetent men out of responsible places.

Many operators have protested against our ruling that they test cream on the ground that whole milk only was delivered at their creameries. IVe have insisted on this point for three reasons. In the first place the law refers to the testing of both products ; then again, the farm separator is so commonly used, that most creameries are equipped and all must soon be equipped to test cream; and, finally, there is a greater likelihood of error in cream analysis than in milk analysis. This error is largely due to the fact that when cream is pipetted-particularly separator cream. or, 
indeed, any cream carrying over twenty-five per cent of fat -it is so thick that it does not flow readily. Eighteen grams is not delivered into the bottle by measuring eighteen cubic centimeters. Then, again, the cream may be frothy or filled with gas bubbles. These errors cause low results, unless they are avoided by the use of a correction table or unless the pipette delivery is weighed.

The correct amount of cream is most surely obtained by weighing the pipette delivery. So many fail in this matter

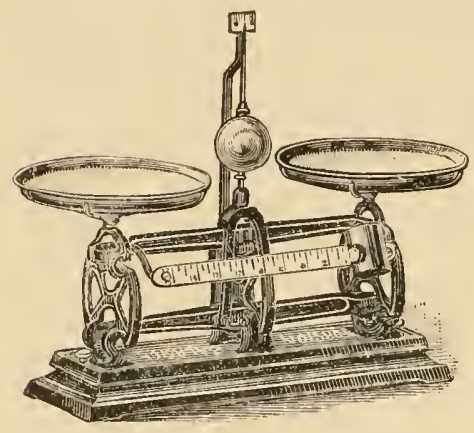
that I want to make it clear. The apparatus needed is simply a small druggist's scale and a few weights. The empty cream bottle on one scale is balanced by the slide or weights on the other. An eighteen gram weight is added and the well mixed cream is pipetted into the cream bottle until the balance swings evenly. The test is then proceeded with as usual. The operation is no more intricate than is the weighing of the butter into the tub in which it is packed. It is precisely the same thing, weighing into a weighed empty package a given weight of the material wanted. The extra time consumed need not be more than a minute to the sample, and as a result of its expenditure far greater accuracy is insured. Every patron taking separator cream to a creamery should insist that the management test eighteen grams of his cream, that they weigh the delivery of the pipette.

That this matter may be made the more clear two pictures of cream test scales are given. The larger one is manufactured by the Springer Torsion Balance Co., 92 Reade Street, New York, in accordance with the snggestions of the Maine experiment station. The empty cream bottle is placed in the specially adapted left-hand pan, is counterpoised by the slide and weights or both, and then eighteen grams of 


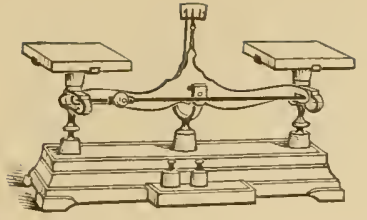

cream are pipetted against an added eighteen gram weight. The snaller cut shows a new scale made by Henry Troemner, 7 io Market Street, Philadelphia, $\mathrm{Pa}$. It is as nearly rust-proof as possible, its three inch bearings are set with agate and its pans are made of porcelain. Its method of use is similar to that indicated for the Springer scale. These scales with weights cost from eight to ten dollars, and both are excellently adapted to the purpose.

ERRORS OF INTENT.

I believe in the "open door" system in a creamery. I would have the management open its books and its testing operations to patrons. I know of one creamery where the test is done in secret and the books kept under lock and key. Secrecy is unwise; publicity disarms suspicion. Dishonest methods of sampling or testing are used occasionally. I believe that "occasionally" is as strong a word as is warranted by the facts. I feel that ninety or ninety-five per cent. of the troubles which agitate the patrons as to the test system are imaginary rather than real. Yet, unfortunately, sometimes errors of intent, deliberate dishonesty, exist. I have, however, no sympathy for a patron who grow1s, or swears, or whines, who claims that he has no recourse, that he is in the hands of a management and must take what they give him, who alleges incompetence or worse, withont striving to correct it or to confirm his allegations by investigation. $\mathrm{He}$ has recourse. He can, if he will, work out his own salvation, either by his own hand, by that of some bright young man or woman, or by that of Uncle Sam. If he is sincere, if he really wants to learn the truth, he can help himself or be helped to attain the right in the manner already cited.

One of my former associates on the Vermont Board of Agriculture was wont to say, that in this era of trusts, which are viewed with some suspicion, there is the one trust we should accept to a greater extent than we do, and that is "trust one another." The present creamery conditions do 
not, in my judgment, warrant the wholesale feeling of distrust which is prevalent among patrons. I would substitute for the word "distrust" one which I think will be found far more helpful as a means of arriving at the truth, one which will satisfy the creamery management far better, the word "investigate."

Do not distrust but investigate. I am confident that most creamery managements will gladly meet candid and sincere patrons more than half-way in the investigation of apparent discrepancies and in the rectification of any proved inaccuracy or injustice. When the day of general mutual investigation dawns in creamery work there will be greater harmony between patron and management, and better work all around.

\author{
UNIVERSITY OF VERMONT \\ and State Agriculttral College \\ TERMONT \\ AGRICULTURAL ENPERIMENT STATION \\ BURLINGTON, VT. \\ Special Bulletin, Octoper, i $\$ 99$. \\ SAMPLING MILK AND CREAM.
}

Dairymen are learning to use the Babcock test more every year upon their individual cows or the entire dairy, either using it themselves or having tests made for them at the creamery or by the experiment station. The results of analses are useless and misleading if obtained on poor samples. There is reason to believe that many do not understand how easy it is to take an incorrect sample.

The following directions for accurate sample taking are printed for the information of the dairymen of the state. Copies will be sent without charge to any address on application to the Experiment Station, Burlington, Vt.

I. To test individual cons.-Provide as many fruit jars (pints or quarts) as there are cows to be tested. (Wide- 
mouthed botttles will do if jars cannot be obtained. If used, they should have tight corks. Narrow-mouthed bottles make accurate sampling difficult and often impossible.)

Label each jar. Into each put preservative to keep the milk sweet. (Use either formalin, sometimes called formal. dehyde, about 20 to 30 drops; or corrosive sublimate, colored with analin red, about ten grains; or potassium bichromate not more than ten grains. Formalin is preferable and nonpoisonous, the other two are poisons and should be handled carefully. These, or some one of these, may be obtained at any drug store or at the local creamery.)

At the first milking pour the entire milk of the cow back and forth from one pail to another not less than three times and then at once dip out approximately a gill (a gill cup on a long handle works well-a small tea-cup will do) and pour into the jar. Close the jar and keep it closed until the next milking. Proceed thus with each cow. At the next milking repeat the operation, adding a second gill of recentlypoured milk from the first cow to the gill taken at the first milking, and similarly with the other cows. Proceed thus for from four to eight successive milkings, keeping the jar closed except when putting in the milk. This makes what is known as the composite sample, one which is much more trustworthy than a sample taken from a single milking. If samples are to be transported, the last sub-sample of each composite sample taken should be made to fill the jor absolutely full to prevent churning while in transit.

Cows vary considerably in the quality of their milk at different stages of lactation. If only infrequent samples are taken, most nearly accurate results (that is, such as will most closely indicate the average quality for the year) will be usually obtained if samples are taken approximately as follows:

Cows calving in the spring: One composite sample six weeks and another six and a half to seren and a half months after calving; or two composite samples, taken about two weeks apart six months after calring.

Corrs calving in the summer: One composite sample eight weeks and another six to seren months after calving; or two 
composite samples, taken about two weeks apart, from three to fire months after calving.

Cows calving in the fall: One composite sample eight to ten weeks and one five and a half to seven months after calving: or two composite samples, taken about two weeks apart, from five to seven months after calving.

Samples taken at other times may give satisfactory results. Prolonged experience has shown, however, that greater likelihood of getting a correct average for the year is attained by sampling at these times.

II. To test the entire dairy as a whole-Prepare a fruit jar as under I. If the churn will hold the entire milking, pour it in and slowly revolve the churn for a couple of minutes, then draw out, taking a gill soon after starting the milk out of the gate. Repeat for several milkings as under $I$.

If the milking is too big for the churn, pour the milk in each large can three or four times back and forth and after the last pouring of each can dip ont at once a gill into a second jar. Haring gills from each can united in the jar, pour these not less than three times. Take one gill and put into jar as under I. The stirring method of sampling from large cans should not be resorted to unless neither of those cited above is practicable. If used, the contents of each large can should be vigoronsly stirred with a long handled dipper round and round, reverse, and dipping deep, from one to three minutes, and a gill taken into a second jar at once on the completion of the stirring of each can of milk, the several united gills to be poured and one gill taken for the final composite sample which should be built up as under I.

III. To test cream from the dairy.-(a.) Shallow setting cream. This class of cream cannot be accurately sampled or tested.

(b.) Deep setting or so-called "gravity" cream. 'The entire lot of cream merged together should be poured as with milk under II. and a gill taken into a jax as under I.

(c.) Separator cream. Proceed as under III. (b.) If thick, stirring may suffice as under Il.

Not less than a pint should be used for a sample. Small samples and narrow-mouthed bottles are untrustworthy.

IV. To test skim milk from a duiry.-(a.) Shallow setting. 
If sour, add a little caustic soda or lye and mix and pour until fluid. Put a gill into a jar without preservative. Make composite sample (four sub-samples) as under 1 .

(b.) Deep setting or so called "gravity." Pour or stir vigorously; take gill from each can and finally pour or stir the united gills and take a single gill. Make composite sample (four sub-samples) as under I. using preservative.

(c.) Separator. Catch skim milk from three to five times each run, distributed throughout the run. Pour and take a gill for composite. Make four sub-sample composite for test as under I., using preservative.

Less time need be spent in mixing skim-milk than with the whole milk or cream.

V. To test buttermilk or zehey.-Draw directly from gate or siphon; make use of the composite sample with preservative.

VI. To check correctness of test at creamery or cheese factory.(a.) Halving creamery sample. IWhen the creamery composite sample is complete and ready for testing, require the operator to furnish one-half of it. Be certain that the sample is thoroughly mixed by pouring, that all the cream from the sides of the jar, cover, etc., is mixed back into the milk or cream, and that the halving is done immediately after the last pouring.

(b.) Duplicating creamery sample. Every time that the party sampling milk or cream at the creamery or on the gathering route samples a patron's milk or cream, the latter may require him to furnish a duplicate sample in a jar controlled by the patron. Duplicate composite samples may be made thus which should test closely alike.

(c.) Sampling at the dairy. Follow directions under II. or III.

Either of these three methods of checking creamery testing is open to objection. In (a) the sample or testing may be incorrectly managed at the creamery, the sample being under control of one of the interested parties, the creamery man. In (b) the sample may be improperly handled by the other interested party, the patron under whose control it is located. Method (c). resembles (b) in 
this respect, and, moreover, results may be vitiated because of error or insufficient care in sampling.

The experiment station strongly urges dairymen as far as possible to make use of the Babcock test at their own homes. It is of more value as used between cow and cow than for settling money matters between man and man.

To such residents of the State as do not consider it advisable to make their own tests, or to have neighbors make them for them, the experiment station offers its services to a limited extent. ${ }^{*}$ It cannot do regular and wholesale testing for any individual or company, but will handle small numbers of samples without charge. It makes but few requirements; as follows :

I. Samples should be carefully taken in accordance with these instructions.

2. Wide mouthed jars should be used.

3. Jars should be filled absolutely full to prevent churning in transit.

4. Express charges should be prepaid. In case jars are desired back again, the express agent should be asked to affix a "free return empty" label on the package and it will be returned without cost.

5. The shipper's name should be placed upon the package for purposes of identification.

Question. You state that changes in feeding will not alter the quality of milk. To what do you ascribe the popular idea to the contrary?

ANSWER. To several canses. In the first place temporary changes frequently occur: that is to say, for a few days, or, indeed, perhaps tor a couple of weeks, a cow may respond to a change of ration with a better quality of milk. This change, however, is but temporary, and she reverts to her regular quality sooner or later, regardless of the change in the feeding. Then again, few people weigh the 1 inilk, and they are apt to fail to discriminate between gain in quantity and gain in quality. Yet, again, the change in the ration

*The writer is authorized by Director E H. Jenkins of the Connecticut Experiment Station, New Haven, Conn., to say that that station will make, free of charge, analyses of milk for citizens of Connecticut. 
may be so excessive (as from an ill-adapted to a well-adapted feed, or the reverse,) that a positive but slight change in the quality of the milk will result. It is now the universal testimony of every experiment station, official and scientific observer, who has worked upon this problem with adequate opportunities and facilities, that the quality of the milk a cow gives is inherent in the animal and cannot permanently be changed by any modification of ration.

Q. I notice that you mention the dilution separators, and speak of them as "delusion separators." Are these the devices which have been advertised in the papers of late for raising cream with cold water?

A. Yes, sir. There are several of these things on the market. They are nothing more nor less than tin cans with some minor variations in their mechanism. The milk diluted with half or more water is set therein, and the cream which rises is skimmed. They are sold at relatively low prices, but, in my judgment, are dear at any price. Rarely, if at all, will they skim closely; and the skim-milk is deteriorated for feeding purposes. It is safe to say, that if a man has a dairy of more than two or three cows he will lose enough in th course of a year, in these two items, to go a long way toward paying for a more expensive and more efficient creaming mechanism. The pretensions of the manufacturers of these cans have been very thoroughly exposed in the publications of several experiment stations. Those who may care to look into this are welcome to send to us for our publication on the subject. The Cornell Experiment Station at Ithaca, New York, has likewise issued matter on this subject. I believe the dilution separators are excellent things for the dairymen to let alone.

Q. I have a herd of cows, and suspect that some of them may not be worth their keep. How nay I most easily and cheaply, and yet surely, find ont about this matter?

A. You need know three things,--the quantity of milk which each cow gives, the quality of milk each gives, and, roughly, the cost of the food which makes it. A small spring balance will furnish the first, the Babcock test the second, 
and observation the third. It is not necessary that the milk be weighed every day. If you weigh the milk of each cow, say, on two or three days in the month, and then multiply results by fifteen or by ten, as the case may be, the results will be close enough for most farmer's purposes. If the samples are taken twice a year, as indicated in the bulletin a few pages back of this, you will get a close notion of the quality. The food need not be weighed, but any observing dairyman can tell pretty closely for himself the appetites of his cows.

This will all take time. It will cost a little something. It will mean mental effort. Many of you no doubt will say you cannot afford to spend the time or money nor the bother with it, that it is not worth while. Yet I will guarantee that a man with a herd of twenty cows for an expenditure not to exceed five dollars in money, and not to exceed two days' time, get a very close notion of the dairy abilities of his sundry animals.

Q. I have a deep setting device apparently in good con dition. Will it be worth my while to replace this by a separator?

A. I cannot tell for a surety. Too many conditions come in to adnit of ones giving a dogmatic yes or no. I think there is no question, however, that at the end of the year a separator (if a good one and properly run) will have yielded more of your special product, be it cream or butter, than can the deep setting device. If, however, the extra initial cost, and the possible extra expense of use more than offset this, it might not be a wise investment. These points, however, are ones which each man can answer for himself better than I can for him. For most dairymen, however, I believe the centrifugal will in the long run prove more satisfactory and more economical.

Q. Is the incorrect Babcock apparatus of which you speak made so designedly, or through carelessness?

A. Probably the latter. This, however, would not affect the result. It makes but little difference to a dead man whether he was shot by a knave or by a fool. 
Q. What do you recommend as a law covering this subject in this State ;

A. I would recommend certification of glassware, inspection of centrifugal testing machines and licensing of operators on examination. Of these I believe the first is the least, and the third the most important point. All of them, however, are desirable.

Q. I notice you recommend the use of balances for weighing cream. This is seldom done, if at all, in Connecticut. What is the result?

A. Such samples as contain more than 25 per cent of fat almost inevitahly will be rated too low, unless the cream is weighed. In other words the patron making thick cream is at a disadvantage unless balances are used. He who makes deep setting cream need not worry about this. He who has a separator and makes thick cream should make life miserable for the creamery proprietor until cream balances are procured, or else should make thin cream.

Q. Cannot some calculation be made to obviate this?

A. Calculation sometimes serves, but results are frequently faulty. It is better to weigh the cream and know that results are correct. The cost of the balances is slight, and there is but little extra work involved. 


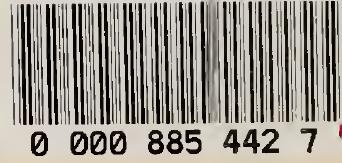


.$H_{5} 5$ 
LIBRARY OF

LIIIIUARY OF CONGRESS

‥

00008 554 ב

0000885442 ?

Hollinger Corp. 